\title{
Input-specific contributions to valence processing in the amygdala
}

\author{
Susana S. Correia and Ki A. Goosens \\ McGovern Institute for Brain Research and Department of Brain and Cognitive Sciences, Massachusetts Institute of Technology, \\ Cambridge, Massachusetts 02139, USA
}

\begin{abstract}
Reward and punishment are often thought of as opposing processes: rewards and the environmental cues that predict them elicit approach and consummatory behaviors, while punishments drive aversion and avoidance behaviors. This framework suggests that there may be segregated brain circuits for these valenced behaviors. The basolateral amygdala (BLA) is one brain region that contributes to both types of motivated behavior. Individual neurons in the BLA can favor positive over negative valence, or vice versa, but these neurons are intermingled, showing no anatomical segregation. The amygdala receives inputs from many brain areas and current theories posit that encoding of positive versus negative valence by BLA neurons is determined by the wiring of each neuron. Specifically, many projections from other brain areas that respond to positive and negative valence stimuli and predictive cues project strongly to the BLA and likely contribute to valence processing within the BLA. Here we review three of these areas, the basal forebrain, the dorsal raphe nucleus and the ventral tegmental area, and discuss how these may promote encoding of positive and negative valence within the BLA.
\end{abstract}

The basic desire to seek reward and avoid punishment shapes virtually all of behavior, and the ability to discriminate between "good" and "bad" environmental cues is critical for guiding choices and maximizing survival. Thus, understanding the brain circuits that encode motivated behaviors is important because it contributes to our knowledge of how we learn, and it is also essential for understanding human disorders associated with abnormal processing of reward and danger (i.e., emotional disorders), such as anxiety, depression, addiction, and post-traumatic stress disorder (PTSD).

The amygdala is one brain area implicated in motivated behaviors and the basolateral complex of the amygdala (BLA) receives information about diverse environmental stimuli from many brain regions. The BLA is thought to encode the association of predictive stimuli with both aversive and appetitive outcomes (Morrison and Salzman 2010; Barberini et al. 2012). Reward and punishment are reinforcers of opposite valence (positive versus negative), and these reinforcers typically lead to opposing behaviors (approach versus avoidance). Many theories have suggested that appetitive and aversive systems act in opponent fashion (Solomon and Corbit 1974; Daw et al. 2002). However, it is unclear how the BLA contributes to this. We do not yet understand the extent to which aversive and appetitive information is processed in parallel BLA circuits, or whether individual BLA neurons are involved in the regulation of both types of motivated behaviors.

In this review, we propose several models by which functional segregation of valence can be achieved in the BLA. These models are based on studies describing how BLA neurons respond to reward and aversive stimuli. We then consider whether three major inputs, known to carry valenced information, support or conflict these models, and also discuss the types of experiments that can best advance our understanding of how behaviors of opposing valence arise from the BLA.

Although this review focuses on input-specific contributions to valence segregation, it is clear that a subset of neurons in the

Corresponding author: kgoosens@mit.edu Article is online at http://www.learnmem.org/cgi/doi/10.1101//m.037887.114.
BLA respond to both valences (Schoenbaum et al. 1999; Paton et al. 2006; Morrison et al. 2011). Thus, we acknowledge that the BLA contributes to more than valence segregation (Belova et al. 2007; Shabel and Janak 2009). In addition, BLA efferents may also make important contributions to valence segregation, a topic which we do not cover here. While this review will consider three different anatomical inputs to the BLA, these anatomical inputs may send several neurochemically distinct inputs into the BLA, providing a means for further segregation of valence. Adding additional complexity, neurotransmitter-specific inputs to the BLA may arise from multiple anatomical sources. By combining floxed viruses with transgenic mouse lines expressing Cre recombinase in neurotransmitter-specific neuronal populations (Nassi et al. 2015), the neuroanatomical and neurochemical contributions to valence segregation may best be studied. However, the paucity of information on these neurochemically distinct subdivisions of anatomical inputs into the BLA limits the information we can provide here. Finally, there are many inputs which may contribute to valence processing, including those carrying primary sensory information about positive and negative reinforcers as well as other brain regions which carry highly processed information about valence. A discussion of all of these points is beyond the scope of this review, but we acknowledge that these are all important and worthwhile topics for future research and consideration.

\section{Models for segregated function in the BLA}

One mechanism by which opposing valence behaviors can be generated is via anatomically distinct, parallel circuits (Fig. 1A). In such a simple model, individual BLA neurons have anatomical segregation of both inputs and outputs, such that inputs that carry appetitive information synapse onto BLA neurons that project

C 2016 Correia and Goosens This article is distributed exclusively by Cold Spring Harbor Laboratory Press for the first 12 months after the full-issue publication date (see http://learnmem.cshlp.org/site/misc/terms.xhtml). After 12 months, it is available under a Creative Commons License (AttributionNonCommercial 4.0 International), as described at http://creativecommons. org/licenses/by-nc/4.0/. 


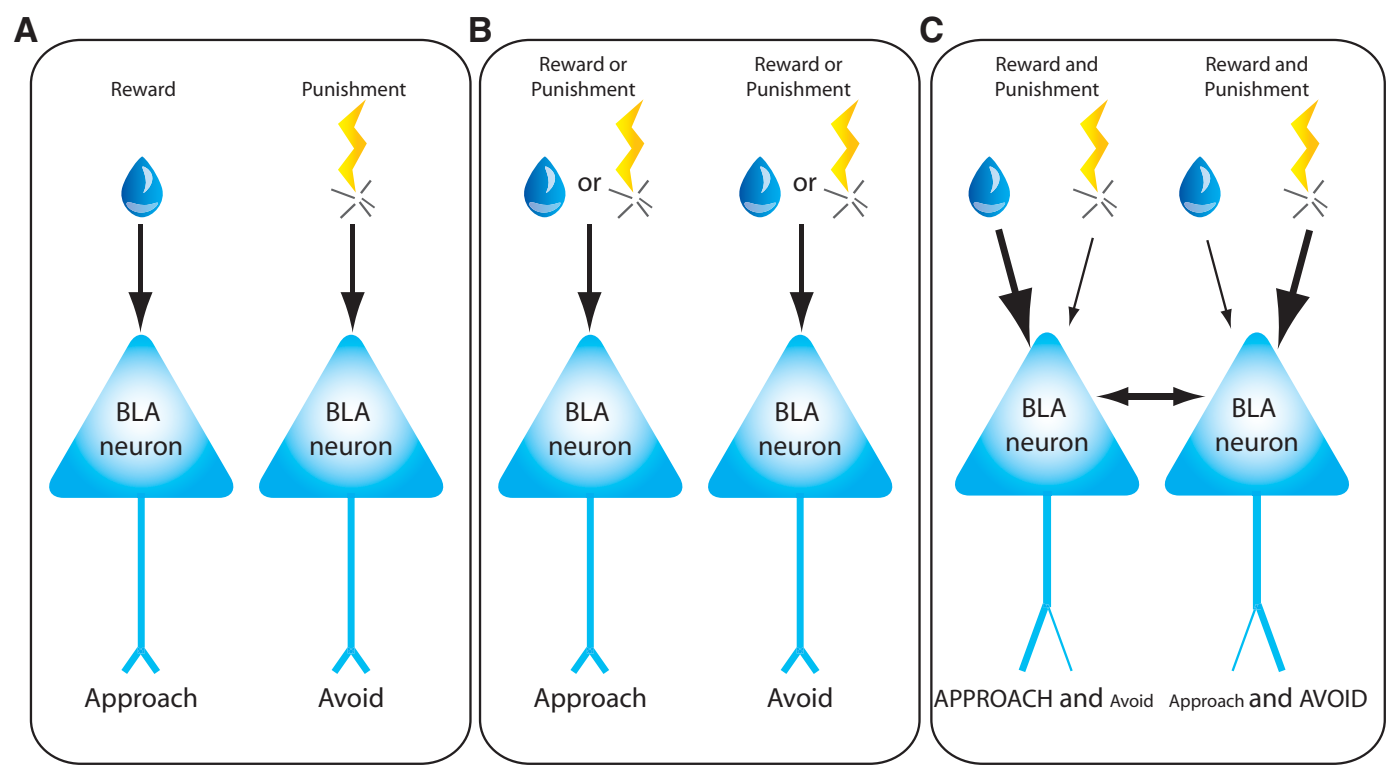

Figure 1. Proposed models representing how opposing valence behaviors are generated by basolateral amygdala neurons (BLA). ( $A$ ) Model 1. Individual BLA neurons have anatomical segregation of both inputs and outputs, such that inputs that carry appetitive information synapse onto BLA neurons that project to brain regions that regulate approach behaviors, while inputs that carry aversive information synapse onto BLA neurons that regulate avoidance behaviors. (B) Model 2. Individual BLA neurons receive inputs conveying both rewarding and aversive reinforcers, but only control either appetitive or avoidance behaviors. (C) Model 3. Individual BLA neurons receive information about both rewarding and aversive reinforcement and project to brain regions that can control both approach and avoidance behaviors. According to this model, the role of BLA neurons in valence driven behaviors is dynamic and may be altered by experience.

to brain regions that regulate approach behaviors, while inputs that carry aversive information synapse onto BLA neurons that regulate avoidance behaviors. However, some findings conflict with this model. For example, while some BLA neurons differentially fire for rewarding or aversive reinforcers, many respond to both, suggesting that BLA neurons receive information about both positive and negative stimuli (Schoenbaum et al. 1999; Paton et al. 2006; Morrison et al. 2011). These data suggest that a certain degree of segregation of neurons encoding positive versus negative valence is likely, but it does not exclude the possibility that the neurons responding to both valences may also have valence-specific roles and/or contribute to arousal or attentional processes. In fact, studies have found similar encoding of spatial information associated with appetitive or aversive stimuli by amygdala neurons, suggesting that neuronal activity in the amygdala may promote spatial attention to sensory stimuli associated with either positive or negative valence experiences (Peck et al. 2013; Peck and Salzman 2014b).

An alternative model posits that individual BLA neurons may respond to both rewarding and aversive reinforcers, but control either appetitive or avoidance behaviors (Fig. 1B). In such a model, inputs containing information about stimuli of opposing valence could serve as a "brake" that acts as an opposing force to the behavioral bias of the individual neuron. For example, appetitive learning could produce synaptic weakening at synaptic inputs for aversive information, while aversive learning could produce synaptic strengthening at such inputs, perhaps as a mechanism to conserve total synaptic load upon single neurons, as has been shown for the intercalated nuclei of the amygdala (Royer and Pare 2003). Single BLA neurons could regulate sensitivity to specific inputs by changing receptor density. In the absence of heterosynaptic mechanisms for conserving synaptic load, sensitivity to differently valenced inputs could also be achieved through altered receptor density if differently valenced inputs use different neurotransmitter systems (Daw et al. 2002). These mechanisms remain theoretically viable, but lack concrete experimental support in the BLA. In a recent study (Namburi et al. 2015), it was found that BLA neurons projecting to the nucleus accumbens (NAc) or the central medial amygdala $(\mathrm{CeM})$ are each altered by both fear and reward conditioning, but in an opposing manner. For example, NAc-projectors displayed synaptic strengthening after reward conditioning but synaptic weakening after fear conditioning, and opposite results were observed for CeM-projectors. These findings were interpreted by the authors to provide support for the model illustrated here (Fig. 1B), but it is still unknown whether the BLA neurons projecting to the NAc and CeM represent segregated populations of neurons encoding appetitive or aversive learning, respectively. In particular, we do not know the extent to which individual BLA neurons project to multiple outputs, such as the striatum, prefrontal cortex, and central nucleus of the amygdala. Each of these BLA efferents have been implicated in the regulation of both appetitive and avoidance responses, but there may exist segregation of valenced behavioral drive in these brain regions as well. Thus, although there is little specific experimental support, this model (Fig. 1B) remains a viable theoretical mechanism by which valenced behaviors are segregated in the BLA.

Yet a third model, which has received little experimental attention, suggests that individual BLA neurons receive information about both rewarding and aversive reinforcement and project to brain regions that can control both approach and avoidance behaviors (Fig. 1C). In this case, the role of BLA neurons in valenced behavior is dynamic and can be altered by the behavioral state or experience of the animal, as has been reported for other brain regions such as the nucleus accumbens (Reynolds and Berridge 2008). Of interest, it was shown that inhibition of BLA neurons that project to the CeM impairs fear expression, but enhances reward learning (Namburi et al. 2015), suggesting that these opposite valence systems operate in opposition. It is unclear if, for instance, the BLA-CeM projection may mediate both valence driven behaviors, or downstream output areas may work in 
opposition to integrate information and select the appropriate behavior. Alternatively, this may result from intra-BLA synaptic connections between BLA neurons that encode reward versus fear. The selection of a behavioral action by a single BLA neuron could be influenced by different patterns of input activity leading to differential neurotransmitter release into target brain regions (El Mestikawy et al. 2011; Hnasko and Edwards 2012). It could also be influenced by state- or experience-dependent bias of processing in target regions such as the nucleus accumbens (Reynolds and Berridge 2008). The ability of neurons to flexibly respond to reinforcers with either approach or avoidance behaviors also facilitates the explanation of counterintuitive behavioral choices. For example, extremely salty solutions are typically avoided, but physiological salt deprivation will produce approach behavior for salty reinforcers (Robinson and Berridge 2013). Also, cues that predict punishing reinforcers are also sometimes chosen over cues that predict the absence of any reinforcer (Barberini et al. 2012). It is not known how the BLA responds in these surprising situations. The vast majority of studies examining the responses of single BLA neurons during appetitive or aversive learning only examine one of these valenced behaviors. To truly understand the extent to which appetitive and aversive systems interact in the BLA, one must study both in the same animal. However, even this approach is complicated because neural networks may have molecular mechanisms to minimize overlap between experiences encoded sequentially in time (Guzowski et al. 2006; Won and Silva 2008). For example, when a BLA neuron is "selected" to participate in encoding an appetitive memory, it may engage molecular mechanisms that decrease the likelihood that it will be selected to participate in aversive memories encoded in the minutes and hours that follow. In this case, valence segregation may not be a predetermined or hardwired property of individual neurons, but rather arises from the experience or history of the animal.

Nevertheless, experimental data showing that mostly segregated populations of amygdala neurons respond to appetitive or aversive stimuli provides support for Models 1 and 3 (Schoenbaum et al. 1999; Paton et al. 2006; Morrison et al. 2011). In agreement with classical amygdala studies showing that aversive learning is mediated by the convergence of the unconditioned and conditioned stimuli within single BLA neurons (Barot et al. 2008; Chung et al. 2011), a recent study found that cells in the amygdala that encode an unconditioned stimulus of opposite valence (and different sensory modality) significantly contributes to both Pavlovian and instrumental associative learning and conditioned responses acquired after learning (Gore et al. $2015 a, b)$. In further support of Model 1, a study found that distinct appetitive and aversive value coding circuits coexist in the amygdala, such that neurons that encode the same valence are more likely to interact with each other (Zhang et al. 2013).

\section{Basal forebrain projection to the BLA}

The BLA receives a dense cholinergic input from the basal forebrain, in particular the nucleus basalis magnocellularis (NB). While neurons in the NB are largely cholinergic, at least one quarter of projection neurons express other neurotransmitters, including GABA, glutamate, and neuropeptides (Detari et al. 1999). It is not known whether these subpopulations of NB neurons also project to the BLA and this diversity in neurochemical signaling must be taken into consideration when interpreting projections originating in the basal forebrain. Many NB neurons respond similarly to both appetitive stimuli and aversive air puffs, while small populations respond selectively to either aversive or appetitive stimuli (Richardson and DeLong 1991). These findings suggest that, as in the BLA, there is some degree of segregation of opposing valenced behaviors within a population of neurons in the $\mathrm{NB}$, while many other neurons respond to both valenced stimuli. Interestingly, a recent study suggests that, in basal forebrain neurons, the response magnitude to reward or punishment is dependent on the anatomical location within the NB. Neurons that respond more strongly to reward are found more superficially in the basal forebrain, while neurons with higher responses to punishment are located in deeper areas of the basal forebrain (Hangya et al. 2015). NB neurons that respond to both positive and negative reinforcers may be part of a network that regulates properties that are shared across both appetitive and aversive tasks, such as arousal or attention (Shabel and Janak 2009). Like the amygdala, basal forebrain neurons selectively respond to spatial cues associated with rewarding outcomes, suggesting that both brain areas may work together to promote attention linked with rewarding experiences (Peck and Salzman 2014a). It is tempting to speculate that NB neurons with segregated function may project to similar neurons in the BLA, while NB neurons that respond to appetitive and aversive stimuli may project to such neurons in the BLA (Fig. 2). However, there is no experimental evidence to either support or disconfirm this hypothesis.

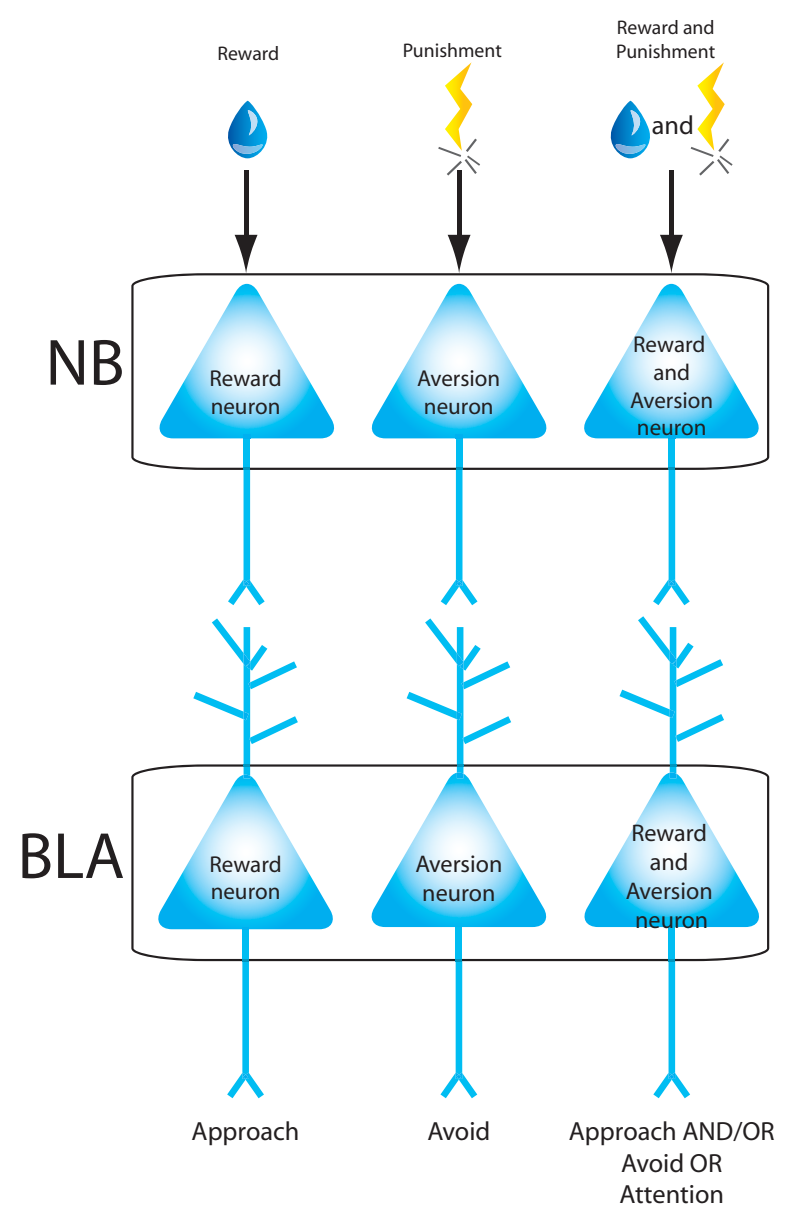

Figure 2. Proposed model representing how neurons in the nucleus basalis magnocellularis (NB) may convey valence information to BLA neurons. This model shows that NB neurons with segregated function may project to similar neurons in the BLA, while NB neurons that respond to appetitive and aversive stimuli may project to such neurons in the BLA. 
Acetylcholine from the NB is poised to regulate neurotransmission in the BLA in a complex manner, because it can produce postsynaptic activation of muscarinic type 1 (M1) receptors (McDonald and Mascagni 2010) or nicotinic receptors (Klein and Yakel 2006) in pyramidal neurons and postsynaptic activation of type 2 muscarinic (M2) receptors (McDonald and Mascagni 2011) or nicotinic receptors (Pidoplichko et al. 2013) in interneurons.

Even though muscarinic receptor subtypes are expressed in different types of neurons in the BLA, agonists of either muscarinic receptor produce similar effects on BLA-dependent aversive behaviors. Pharmacological agonism of these receptors immediately after training on an inhibitory avoidance task improved task performance (Power et al. 2003; Tinsley et al. 2004). Conversely, lesions of the $\mathrm{NB}$, thought to have a disproportionately larger effect on BLA cholinergic inputs relative to inputs to other brain areas, impaired the acquisition and consolidation of inhibitory avoidance, an effect that was attenuated by infusion of muscarinic receptor agonists in the BLA (Power and McGaugh 2002; Tinsley et al. 2004). Collectively, these results indicate that the cholinergic projections into the BLA facilitate learning of an aversive inhibitory avoidance task (Power and McGaugh 2002; Tinsley et al. 2004). Similarly, contextual fear conditioning memories were increased by muscarinic receptor agonism (Cangioli et al. 2002) and impaired by muscarinic receptor antagonism (Passani et al. 2001; Tinsley et al. 2004) in the BLA. Furthermore, an M1 receptor knockout mouse showed deficits in auditory fear learning (Miyakawa et al. 2001; Tinsley et al. 2004). Though far lessstudied, nicotinic receptors in the BLA also modulate aversive behaviors. For instance, blockade of nicotinic receptor during an inhibitory avoidance task reduced avoidance behavior but this effect was only observed in young animals (Blozovski and Duméry 1987; Tinsley et al. 2004).

While most studies have focused on the role of cholinergic projections into the BLA in aversive behaviors, the effects of acetylcholine receptor agonism in the BLA have also been studied during appetitive behaviors. Blockade of muscarinic receptors in the BLA also impairs the performance on a conditioned place preference task (McIntyre et al. 1998) but it is unclear if the effects of acetylcholine are mediated through pyramidal or interneurons in the BLA. Likewise, it is not known if inhibitory avoidance learning mediated by nicotinic receptors emerge from the effects of acetylcholine on pyramidal neurons or interneurons in the BLA, but electrophysiological recordings have found more pronounced effects of nicotinic receptor blockade in interneurons (Unal et al. 2015). Regardless, the similar effects of cholinergic receptor manipulations in the BLA on appetitive and aversive tasks suggest that acetylcholine-induced plasticity mechanisms may be similar across different task-dependent populations of neurons in the BLA.

Studies have provided a variety of mechanisms by which signaling through muscarinic receptors in BLA neurons promotes neuronal excitability, such as the suppression of potassium currents and reduction of the slow afterhyperpolarization of action potentials (Washburn and Moises 1992; Womble and Moises 1993). In agreement with these data, long-term potentiation in the lateral amygdala was reduced by muscarinic receptor blockade. However, in other cases muscarinic receptor activation in the BLA can also decrease neuronal excitability (Power and Sah 2008).

While agonism of acetylcholine receptors in the BLA was shown to improve memory of both aversive and appetitive driven learning tasks, more recent studies have revealed that the relationship between NB activity and changes in firing of BLA neurons is not so simple (Unal et al. 2015). The influence of the NB is different in interneurons versus pyramidal neurons because different cholinergic receptors are expressed by these cell types. Even within pyramidal neurons, the effect of NB activity depends on the firing rate of the BLA neuron; this is because there is state-dependent recruitment of intracellular cascades through BLA muscarinic receptors. Thus, it is clear that the effects of the NB on the BLA may be highly task-dependent and further studies are necessary to understand how task-dependent firing patterns vary across the three classes of NB neurons (Fig. 2).

\section{Dorsal raphe nuclei projections to the BLA}

The dorsal raphe nucleus (DRN) sends a heavy projection to the BLA (Vertes 1991; Burghardt and Bauer 2013). Nearly two-thirds of DRN neurons express serotonin (5-HT) and these serotonergic neurons strongly innervate the BLA (Steinbusch et al. 1981). Nonetheless, there is heterogeneity in the neurotransmitter and neuropeptide content of DRN neurons (Hokfelt et al. 2000), and also considerable variability in the responses of these neurons during emotionally valenced tasks. Some DRN neurons encode both expected and received reward value (Nakamura 2013) and DRN neurons also have been shown to respond to punishment (Montagne-Clavel et al. 1995; Schweimer and Ungless 2010). It is not known whether the neurochemically distinct DRN populations all respond to reward and punishment and whether these populations of cells also project to the BLA. It is also clear that some DRN neurons co-release both 5-HT and glutamate (Liu et al. 2014); thus, the DRN may modulate BLA neurons through other neurotransmitters besides 5-HT.

Multiple studies have linked serotonergic DRN neurons to valenced behavior. For example, virtually all serotonergic DRN neurons show phasic firing changes to punishment, and approximately half display phasic firing changes to reward-predictive cues (Cohen et al. 2015). Using the Pet1 promoter, which enables selective targeting of a subset of serotonergic neurons, $65 \%$ of optogenetically identified DRN-Pet1 neurons show increased firing after reward-predictive cues (Liu et al. 2014). Interestingly, expected or received reward size can also modulate DRN neuronal firing in a reward task (Nakamura et al. 2008), but it is not clear whether these neurons are serotonergic. In addition, optogenetic activation of DRN-Pet1 neurons acts as a reward signal to bias exploratory behavior in mice and facilitates discriminatory learning in an odor-reward association task (Liu et al. 2014; Luo et al. 2015). These results suggest that, at the stimulation patterns tested, DRN-Pet1 neurons represent a subpopulation of serotonergic neurons that promote reward behaviors in a glutamate and serotonin-dependent manner (Liu et al. 2014; Luo et al. 2015). One possibility is that increased reward learning is due to serotonin-mediated reduction in impulsivity, as previous studies found that serotonergic neurons in the DRN increase firing during a delay period before reward delivery and that optogenetic stimulation of serotonergic DRN neurons increases correct waiting behavior and performance during a delayed reward task (Miyazaki et al. 2011, 2014). When examining tonic firing within longer time scales, it was found that distinct populations of serotonergic neurons respond with higher firing rates during blocks of appetitive versus aversive trials, and vice versa (Cohen et al. 2015). In addition, during reward tasks, many DRN neurons show strong correlations between tonic activity levels throughout the task and activity in response to either a reward predictive cue or the reward itself (Bromberg-Martin et al. 2010). Because of the segregation of function within the DRN, it is possible that these distinct DRN neurons project to different populations of neurons within the BLA (Fig. 3), but this remains to be tested.

Two families of serotonergic receptors, 5-HT2 and 5-HT3, are expressed in the BLA, but the 5-HT2 receptor family is the most 


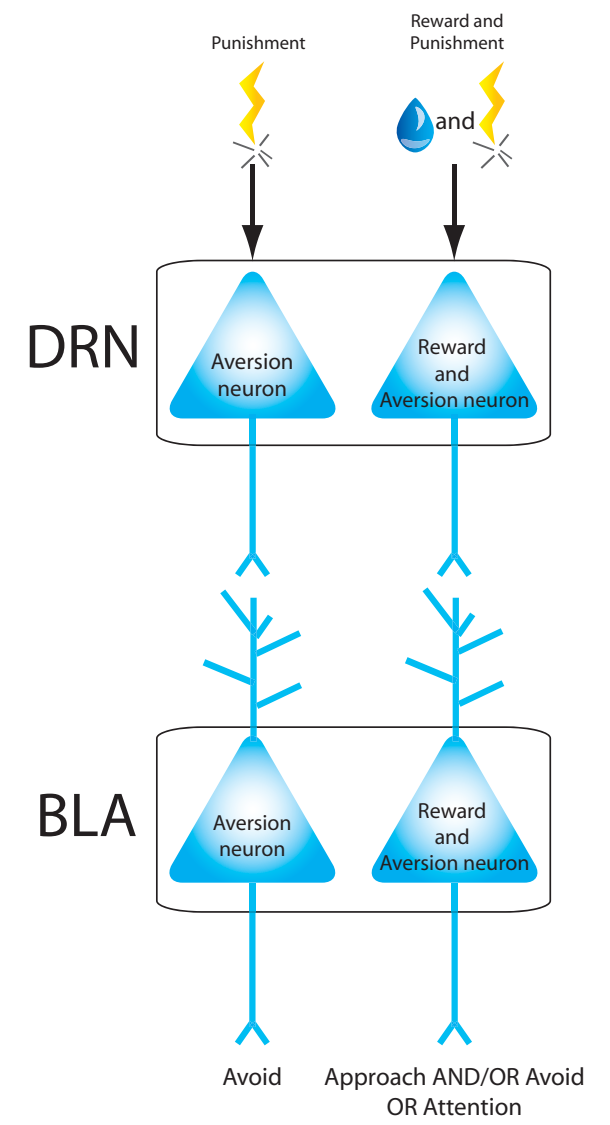

Figure 3. Proposed model representing how neurons in dorsal raphe nucleus (DRN) may convey valence information to BLA neurons. According to this model: DRN neurons that respond to aversive stimuli project to BLA neurons that respond to aversive stimuli only; DRN neurons that respond to aversive and appetitive stimuli project to BLA neurons also responsive to both types of stimuli.

abundant. These receptors are found in virtually all excitatory neurons and the majority of parvalbumin-positive $(\mathrm{PV}+)$ interneurons in the BLA (McDonald and Mascagni 2007). 5-HT3 receptors are almost exclusively localized to GABAergic neurons in the BLA (Mascagni and McDonald 2007) and consequently, their expression appears sparse throughout this area. The $1 \mathrm{~A}$ serotonin receptors (5-HT1A) are not expressed in BLA neurons, but are expressed in the raphe axon terminals targeting the BLA, where they act as autoreceptors and modulate serotonergic release in the BLA. Activation of these receptors limits the release of serotonin at nerve terminals and affects overall serotonergic tone (for review, see Holmes 2008).

Extracellular serotonin in the BLA is increased by stress, fear, and anxiety (Kawahara et al. 1993; Fernandes et al. 1994; Gargiulo et al. 1996; Rueter and Jacobs 1996), but the presence of different receptors in both excitatory and inhibitory cells of the BLA suggests that the effects of serotonin on aversive processing are complex. The use of pharmacological antagonists and protein manipulations reveal a specific role for the 5 -HT2C receptors in anxiety. These receptors promote neuronal excitation by coupling to phospholipase $\mathrm{C}$ and increasing intracellular calcium. For instance, overexpression of 5-HT2C receptors in the forebrain (including the BLA) produces anxiety (Kimura et al. 2009) and selective serotonin reuptake inhibitors (SSRIs) increase the expression of fear memory (Burghardt et al. 2007). Conversely, 5-HT2C knockout mice show decreased anxiety (Heisler et al. 2007) and
5-HT2C antagonists block the enhancement of fear expression by SSRIs. One hypothesis is that activation of these receptors may increase anxiety by elevating the serotonin levels in the BLA, since 5-HT2C antagonists block increases in serotonin during a stressful event. In agreement with this, rats subjected to inescapable shock stress show increased serotonin release in the BLA during a social exploration test and decreased social exploration time, which is reversed by 5 -HT2C receptor antagonists in the BLA before the social test (Christianson et al. 2010). Altogether, these results suggest that activation of 5 -HT2C receptors in the BLA mediates increases in fear expression and anxiety, while reduced activity at this type of receptor is anxiolytic.

The BLA 5-HT3 receptors, which are the only serotonin receptors that form ligand-gated channels permeable to cations (Barnes and Sharp 1999), are also linked to aversive processing in the BLA. 5-HT3A receptor knockout mice showed increased fear learning (Bhatnagar et al. 2004). Humans carriers of an allelic variant of a SNP in the HTR3A gene, C178T, which is associated with increased 5-HT3 receptor expression in vitro (Niesler et al. 2001) show lower scores for anxiety-related traits and reduced amygdala activity in response to threatening stimuli (Melke et al. 2003; Iidaka et al. 2005). These results suggest that higher levels of 5-HT3 receptors may constrain aversive processing, while lower levels of 5-HT3 receptor may promote fear learning and anxiety, consistent with the idea that these receptors are mostly located in BLA inhibitory neurons and may act to reduce the excitability of BLA projection neurons (Mascagni and McDonald 2007). Further study of the role of these receptors in the amygdala will be important to establish a clear role between behavior and 5-HT3 receptor function.

Finally, the 5-HT1A receptor also regulates aversive processing. 5-HT1A agonists infused into the BLA impair the expression of context fear conditioning (Stiedl et al. 2000; Li et al. 2006) and decrease the acquisition and expression of a conditioned defeat task (Morrison and Cooper 2012). The role of 5-HT1A receptors in anxiety is unclear, since 5-HT1A agonists applied into the rat BLA can both reduce and increase anxiety (Holmes 2008). These results may be explained by differential effects of 5-HT1A agonists on BLA neuronal activity. Some studies found that application of 5-HT1A receptor agonists in the BLA inhibits neuronal excitability and the inhibitory actions of 5-HT on BLA neurons can be prevented by a 5 -HT1A receptor antagonist (Cheng et al. 1998; Wang et al. 1999; Stein et al. 2000). Other studies found that 5-HT1A receptor agonists can also suppress GABA interneuron activity in the BLA (Koyama et al. 1999; Koyama et al. 2002). Exposure to stress can also impact the BLA through desensitization of 5-HT1A autoreceptors (Laaris et al. 1997; Lanfumey et al. 1999; Gartside et al. 2003; Froger et al. 2004), likely impairing inhibition of serotonin release at these terminals in the BLA.

Unfortunately, much less is known about the role of serotonin in reward processing. It is not known how extracellular levels of serotonin in the BLA are altered by reward processing, but selective pharmacological depletion of serotonin in the BLA does enhance the expression of learned appetitive behaviors (Man et al. 2012), and also impairs probabilistic discriminative and reversal reward learning (Rygula et al. 2014). Only a few studies have examined the contribution of specific serotonin receptors to reward processing in the context of drug addiction or food reward. For example, a 5HT-2 receptor agonist in the BLA decreased rewardseeking lever presses (McCool et al. 2014) and higher levels of 5HT3A in the BLA are predictive of stronger Pavlovian approach behaviors in a task in which cues predict food delivery (Barker et al. 2014). Thus, while it is clear that serotonin can modulate reward, there remains much to be discovered about the mechanisms by which this is achieved. 
It is interesting that activation of 5HT-2 or 5HT-3 receptors in the BLA seems to have opposite effects on positive versus aversive behaviors. Activity through the 5HT-2 receptors promotes fear and decreases reward seeking (McCool et al. 2014) and activity at 5HT-3A receptors decreases anxiety but increases food approach behavior (Melke et al. 2003; Iidaka et al. 2005; Barker et al. 2014). In addition, 5HT-2C and 5HT-3 receptors seem to have opposite functions during learning tasks driven by either positive or negative valence. For instance 5HT-2C receptor activity or lack of 5HT-3A receptors can promote fear (Bhatnagar et al. 2004; Burghardt et al. 2007). This may be due to the opposite effects of each receptor on neuronal excitability since 5HT-2C receptors would be expected to increase excitability of excitatory neurons in the BLA (Barnes and Sharp 1999), while the 5HT-3A receptors found in GABAergic neurons in the BLA are thought to indirectly inhibit pyramidal cells by activating postsynaptic interneurons (but also see Sugita et al. 1992).

\section{Ventral tegmental area projection to the BLA}

Many dopamine neurons innervating the BLA originate from cells situated within multiple subgroups of the ventral tegmental area (VTA) (de la Mora et al. 2010). Dopamine is frequently associated with reward: both unexpected rewards and cues that predict rewards trigger phasic firing in $\sim 75 \%$ of dopaminergic VTA neurons (Romo and Schultz 1990; Schultz 2007). While it is often assumed that this reward-related activity is present throughout the extent of the VTA, this has not been demonstrated. For instance, it is thought that VTA neurons activated by reward are located in the dorsal VTA, but it is not known whether ventral VTA neurons also respond to reward (Ungless et al. 2004; Brischoux et al. 2009). The response of VTA neurons to aversive stimuli is anatomically segregated: dorsal VTA neurons are inhibited by aversive stimuli while ventral VTA neurons are excited by these stimuli (Brischoux et al. 2009). Others have reported valence segregation more broadly within midbrain dopamine neurons: neurons excited by positive valence and inhibited by negative valence were found in the VTA and ventromedial substantia nigra (SN), while a second neuron type excited by both valences was found in the dorsolateral SN (Matsumoto and Hikosaka 2009). While inhibition of VTA dopamine neurons when the reward is omitted is driven by the lateral habenula (Matsumoto and Hikosaka 2007), such inhibitory drive is not responsible for the inhibition of VTA dopamine neurons by aversive events (Tian and Uchida 2015). Thus, it is possible that dopaminergic VTA neurons are anatomically segregated by valence, and single neurons respond oppositely to aversive and appetitive stimuli. Alternatively, there may be a dopaminergic VTA system that primarily signals reward, and a second system en- coding a feature common to both aversive and appetitive stimuli, such as salience.

Dopamine can impact BLA function through numerous receptors. Dopamine type 1 receptors (D1 and D5) have widespread expression within the BLA with D1 receptors mainly found in dendritic spines and D5 receptors in terminals (Muly et al. 2009). Because D5 receptors have higher affinity for dopamine, it has been suggested that dopamine presynaptic actions may predominate in the BLA at low levels of dopamine, while postsynaptic effects increase and dominate as dopaminergic drive increases. Dopamine type 2 receptors (D2) have also been observed in the BLA (Maltais et al. 2000), but the localization of these receptors is unclear and the level of expression of $\mathrm{D} 2$ receptors is controversial (de la Mora et al. 2010).

Dopamine is clearly important for modulating BLA-dependent aversive learning. Dopamine levels in the BLA are increased by aversive learning tasks (Yokoyama et al. 2005) and also during stressful events (Coco et al. 1992; Inglis and Moghaddam 1999), suggesting that dopamine facilitates aversion. In agreement with this, pharmacological agonism of D1 receptors in the BLA enhances neuronal firing evoked by stimulation of auditory inputs in some BLA neurons (Chang and Grace 2015). Providing further support, both D1 receptor antagonism and genetic ablation of D1 receptors in the BLA impair the acquisition of fear memories (Greba and Kokkinidis 2000; Fadok et al. 2009). The role of the D2 receptor in BLA-dependent aversive memory is far less studied, but 
D2 receptor antagonism immediately after inhibitory avoidance training impairs retention of this task (Lalumiere et al. 2004) and also inhibits the acquisition of fear potentiated startle (de la Mora et al. 2010).

Dopamine in the BLA also modulates reward-related behaviors and its levels are increased in the BLA during appetitive learning paradigms (Hori et al. 1993; Harmer and Phillips 1999). D1 receptor blockade in the BLA impairs the acquisition of an instrumental appetitive task, implicating these receptors in reward learning (Andrzejewski et al. 2005). Moreover, both D1 and D2 receptor activation in the BLA mediates cue-induced reinstatement of drug self-administration (See et al. 2001, 2003; Berglind et al. 2006). Additionally, D1 receptor antagonism enhances operant responding for cocaine (Hurd et al. 1997).

Overall, dopamine enhances both aversive and appetitive processing within the BLA, and the effects of dopamine receptor manipulation on valence processing are similar across both dopamine type 1 and type 2 families of receptors. This is consistent with findings from in vitro studies showing that dopamine increases the excitability of BLA projection neurons via mechanisms involving both D1 and D2 receptors on both projection and inhibitory neurons (Kroner et al. 2005). Dopamine may also facilitate glutamatergic neurotransmission. Anatomically, dopaminergic terminals form nonsynaptic appositions with glutamatergic axon terminals and synaptic contacts with distal dendrites of pyramidal neurons in the BLA (Muller et al. 2009) and D1 receptor expression is partially overlapped with the NR1 subunit of NMDA receptors in endomembrane distributions in the soma and dendrites of BLA projection neurons (Pickel et al. 2006). Also, dopamine-induced enhancement of feedforward inhibition into interneurons within the BLA is permissive for the induction of long-term potentiation at BLA synapses due to disinhibition of excitatory neurons (Bissiere et al. 2003).

It is clear that populations of dopaminergic VTA neurons are activated by appetitive and aversive stimuli, and that plasticity of BLA neurons is enhanced by dopamine released during emotionally valenced tasks. Thus, anatomically segregated VTA inputs could mediate either positive versus negative or reward versus salience valenced neuronal segregation in the BLA (Fig. 4). To distinguish between these possibilities, we must understand whether neurons in the ventral VTA represent salience or aversion and also explore the extent to which the dorsal versus ventral VTA project to different cell populations within the BLA.

\section{Conclusions}

Most studies examining the response of single BLA neurons during appetitive and aversive behaviors only focus on a single valence-driven behavior. While these experiments are important for determining the role of the BLA during aversive or appetitive behaviors, they do not further our understanding of how these circuits are segregated within the BLA.

The level of segregation of valencedependent inputs into the amygdala may vary depending on the afferent structure. For instance, in the NB, neurons respond to either aversive or appetitive stimuli, or to both valences, raising the possibility that inputs from the NB neurons with segregated function may project to similar neurons in the BLA (in agreement with the model shown in Fig. 1A), while NB neurons that respond to appetitive and aversive stimuli may project to such neurons in the BLA (Fig. 2 , in agreement with the models depicted in Fig. 1B,C). Dopaminergic VTA neurons may be anatomically segregated by valence (Fig. 4, left; in agreement with the model shown in Fig. $1 \mathrm{~A})$, or there may be a dopaminergic VTA system that primarily signals reward, and a second system that encodes both aversive and appetitive stimuli (Fig. 4, right; supporting a combination of the models in Fig. 1). A different picture emerges when considering the inputs from the DRN (Fig. 3). In this case, DRN neurons that respond to aversive stimuli could project to BLA neurons that respond to aversive stimuli only (in accordance with the model shown in Fig. 1A) and DRN neurons that respond to aversive and appetitive stimuli could project to BLA neurons also responsive to both types of stimuli (as depicted in the models of Fig. $1 \mathrm{~B}$ or $\mathrm{C})$. It is likely that all three models presented in Figure 1 may coexist and determine valence-modulated behaviors by the amygdala. Further studies will be necessary to determine the role of different inputs and their contribution in amygdala modulation of these behaviors.

Studying both aversive and appetitive behaviors within a single subject is essential for answering the question of how valence is processed within the amygdala and other brain areas. To address the fundamental issues of how anatomical wiring contributes to functional segregation of opposing valence stimuli within the BLA, it is important to combine circuit dissection with behavioral and electrophysiology recordings. Below, we propose approaches that address some of the issues we raise in this review.

There are many sensory and cortical afferents that project to the BLA (Pitkanen 2000). Many of these BLA inputs consist of
A

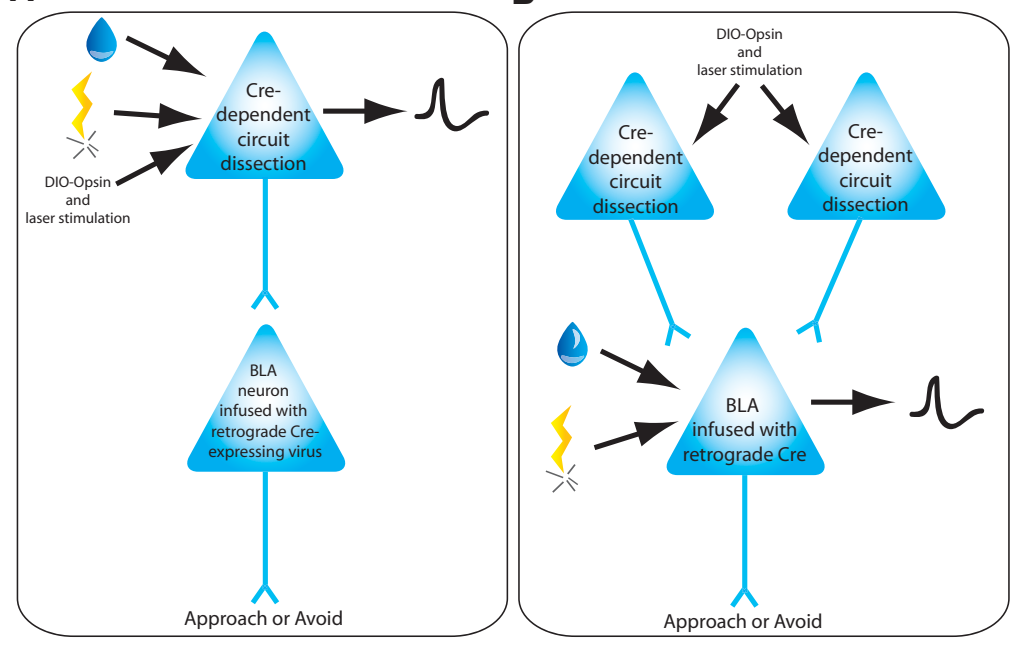

Figure 5. Proposed experimental approaches to investigate how positive and negative valence stimuli modulate BLA neuronal projectors $(A)$ and BLA neurons $(B)$. To identify whether inputs into the BLA carry information about positive and negative valence, BLA projectors will be identified using opsin-assisted circuit dissection by using infusion of retrograde virus encoding Cre recombinase within the BLA and laser stimulation in the brain area projecting to the BLA. $(A)$ When recording in the brain region(s) that projects to the BLA, during behaviors driven by aversive and appetitive learning, we will be able to identify neurons projecting to the BLA (expressing the opsin in a Cre-dependent manner) and that encode positive and/or negative valence. $(B)$ Using the same approach while recording BLA neuronal activity during behaviors driven by aversive and appetitive learning, we can determine whether BLA neurons encoding positive and/or negative valence information receive projections from different inputs. 
neuronal populations that respond to either both or only one type of valenced stimulus, but it is unclear whether these subpopulations of neurons all project to the BLA. To answer this question, it is necessary to study the firing patterns induced by both appetitive and aversive stimuli in neurons known to project to the BLA (Fig. 5A). By infusing a retrograde virus expressing Cre recombinase in the BLA and a second virus expressing opsin proteins in a Cre-dependent manner in a BLA afferent, one could combine photoactivation with electrophysiological recordings to identify those neurons in the afferent structure that project to the BLA. This could then be followed by electrophysiological recordings of neurons within the BLA afferent during presentation of aversive and appetitive stimuli to characterize the valence profile of each BLA-projecting neuron. Additionally, photoinhibition or photostimulation of these neuronal inputs to the BLA during aversive or appetitive behavioral tasks could help us better understand the contribution of these inputs to valenced behaviors, especially if combined with activity-dependent expression of the proteins that allow inhibition or activation of neuronal ensembles activated by opposite valence experiences (Redondo et al. 2014; Gore et al. 2015a,b).

Using the same approach while recording in the BLA would allow one to determine if BLA neurons that respond only to aversive, appetitive or both types of stimuli receive inputs from the same brain area or distinct brain areas. In addition, while stimulating different inputs into the BLA and recording BLA neuronal activity, one could determine whether: (1) different inputs can modulate the same neuron; (2) neurons modulated by different inputs respond to appetitive, aversive or both types of stimuli, and (3) manipulation of each input can drive a neuron to respond to either aversive or appetitive stimuli.

These are just a few examples of the kind of questions scientists may address in the near future. While it is already recognized that the BLA is important for valenced behavior, a more sophisticated understanding of functional compartmentalization within the BLA is essential for understanding how the BLA regulates emotional processing. Studying how afferent projections converge or segregate into populations of BLA neurons will help us determine how these inputs modulate patterns of neuronal activity and how different patterns of amygdala neuronal firing modulate valenced behaviors. This knowledge may facilitate the detection and correction of patterns of amygdala neuronal activity associated with pathological behaviors. Furthermore, dissecting the molecular mechanisms involved in achieving these patterns of neuronal activity induced by different afferents within populations of amygdala neurons will allow us to identify specific molecular pathways that represent potential targets for the treatment of mental disorders. An imbalance in approach and avoidance may contribute to many mental health disorders including addiction, anxiety, and post-traumatic stress disorder. Understanding the extent to which appetitive and aversive circuits in the BLA are distinct or convergent facilitates the study of these circuits in the context of animal models of emotional disorders.

\section{Acknowledgments}

We thank Anna McGrath for comments on the manuscript. This research was funded by the National Institute of Mental Health (R01 MH084966), the U.S. Army Research Office, and the Defense Advanced Research Projects Agency (grant W911NF-101-0059) to K.A.G.

\section{References}

Andrzejewski ME, Spencer RC, Kelley AE. 2005. Instrumental learning, but not performance, requires dopamine D1-receptor activation in the amygdala. Neuroscience 135: $335-345$.
Barberini CL, Morrison SE, Saez A, Lau B, Salzman CD. 2012. Complexity and competition in appetitive and aversive neural circuits. Front Neurosci 6: 170.

Barker JM, Zhang H, Villafane JJ, Wang TL, Torregrossa MM, Taylor JR. 2014. Epigenetic and pharmacological regulation of 5HT3 receptors controls compulsive ethanol seeking in mice. Eur J Neurosci 39: 999-1008.

Barnes NM, Sharp T. 1999. A review of central 5-HT receptors and their function. Neuropharmacology 38: 1083-1152.

Barot SK, Kyono Y, Clark EW, Bernstein IL. 2008. Visualizing stimulus convergence in amygdala neurons during associative learning. Proc Natl Acad Sci 105: 20959-20963.

Belova MA, Paton JJ, Morrison SE, Salzman CD. 2007. Expectation modulates neural responses to pleasant and aversive stimuli in primate amygdala. Neuron 55: 970-984.

Berglind WJ, Case JM, Parker MP, Fuchs RA, See RE. 2006. Dopamine D1 or $\mathrm{D} 2$ receptor antagonism within the basolateral amygdala differentially alters the acquisition of cocaine-cue associations necessary for cue-induced reinstatement of cocaine-seeking. Neuroscience 137: 699-706.

Bhatnagar S, Sun LM, Raber J, Maren S, Julius D, Dallman MF. 2004. Changes in anxiety-related behaviors and hypothalamic-pituitary-adrenal activity in mice lacking the 5-HT-3A receptor. Physiol Behav 81: 545-555.

Bissiere S, Humeau Y, Luthi A. 2003. Dopamine gates LTP induction in lateral amygdala by suppressing feedforward inhibition. Nat Neurosci 6: $587-592$.

Blozovski D, Duméry V. 1987. Development of amygdaloid cholinergic mediation of passive avoidance learning in the rat. II. Nicotinic mechanisms. Exp Brain Res 67: 70-76.

Brischoux F, Chakraborty S, Brierley DI, Ungless MA. 2009. Phasic excitation of dopamine neurons in ventral VTA by noxious stimuli. Proc Natl Acad Sci 106: 4894-4899.

Bromberg-Martin ES, Hikosaka O, Nakamura K. 2010. Coding of task reward value in the dorsal raphe nucleus. J Neurosci 30: 6262-6272.

Burghardt NS, Bauer EP. 2013. Acute and chronic effects of selective serotonin reuptake inhibitor treatment on fear conditioning: implications for underlying fear circuits. Neuroscience 247: 253-272.

Burghardt NS, Bush DE, McEwen BS, LeDoux JE. 2007. Acute selective serotonin reuptake inhibitors increase conditioned fear expression: blockade with a 5-HT(2C) receptor antagonist. Biol Psychiatry 62: 1111-1118.

Cangioli I, Baldi E, Mannaioni PF, Bucherelli C, Blandina P, Passani MB. 2002. Activation of histaminergic $\mathrm{H} 3$ receptors in the rat basolateral amygdala improves expression of fear memory and enhances acetylcholine release. Eur J Neurosci 16: 521-528.

Chang CH, Grace AA. 2015. Dopaminergic modulation of lateral amygdala neuronal activity: differential D1 and D2 receptor effects on thalamic and cortical afferent inputs. Int J Neuropsychopharmacol 18: pyv015.

Cheng LL, Wang SJ, Gean PW. 1998. Serotonin depresses excitatory synaptic transmission and depolarization-evoked $\mathrm{Ca}^{2+}$ influx in rat basolateral amygdala via 5-HT1A receptors. Eur J Neurosci 10: 2163-2172.

Christianson JP, Ragole T, Amat J, Greenwood BN, Strong PV, Paul ED, Fleshner M, Watkins LR, Maier SF. 2010. 5-hydroxytryptamine 2C receptors in the basolateral amygdala are involved in the expression of anxiety after uncontrollable traumatic stress. Biol Psychiatry 67: $339-345$.

Chung A, Barot SK, Kim JJ, Bernstein IL. 2011. Biologically predisposed learning and selective associations in amygdalar neurons. Learn Mem 18: $371-374$

Coco ML, Kuhn CM, Ely TD, Kilts CD. 1992. Selective activation of mesoamygdaloid dopamine neurons by conditioned stress: attenuation by diazepam. Brain Res 590: 39-47.

Cohen JY, Amoroso MW, Uchida N. 2015. Serotonergic neurons signal reward and punishment on multiple timescales. eLife $\mathbf{4}$.

Daw ND, Kakade S, Dayan P. 2002. Opponent interactions between serotonin and dopamine. Neural Netw 15: 603-616.

de la Mora MP, Gallegos-Cari A, Arizmendi-Garcia Y, Marcellino D, Fuxe K. 2010. Role of dopamine receptor mechanisms in the amygdaloid modulation of fear and anxiety: structural and functional analysis. Prog Neurobiol 90: 198-216.

Detari L, Rasmusson DD, Semba K. 1999. The role of basal forebrain neurons in tonic and phasic activation of the cerebral cortex. Prog Neurobiol 58: 249-277.

El Mestikawy S, Wallen-Mackenzie A, Fortin GM, Descarries L, Trudeau LE. 2011. From glutamate co-release to vesicular synergy: vesicular glutamate transporters. Nat Rev Neurosci 12: 204-216.

Fadok JP, Dickerson TM, Palmiter RD. 2009. Dopamine is necessary for cue-dependent fear conditioning. J Neurosci 29: 11089-11097. 
Fernandes C, Andrews N, File SE. 1994. Diazepam withdrawal increases $[3 \mathrm{H}]-5-\mathrm{HT}$ release from rat amygdaloid slices. Pharmacol Biochem Behav 49: $359-362$.

Froger N, Palazzo E, Boni C, Hanoun N, Saurini F, Joubert C, Dutriez-Casteloot I, Enache M, Maccari S, Barden N, et al. 2004. Neurochemical and behavioral alterations in glucocorticoid receptor-impaired transgenic mice after chronic mild stress. J Neurosci 24: $2787-2796$

Gargiulo PA, Viana MB, Graeff FG, Silva MA, Tomaz C. 1996. Effects of anxiety and memory of systemic and intra-amygdala injection of 5-HT3 receptor antagonist BRL 46470A. Neuropsychobiology 33: $189-195$.

Gartside SE, Johnson DA, Leitch MM, Troakes C, Ingram CD. 2003. Early life adversity programs changes in central 5-HT neuronal function in adulthood. Eur J Neurosci 17: 2401-2408.

Gore F, Schwartz EC, Brangers BC, Aladi S, Stujenske JM, Likhtik E, Russo MJ, Gordon JA, Salzman CD, Axel R. 2015a. Neural representations of unconditioned stimuli in basolateral amygdala mediate innate and learned responses. Cell 162: 134-145.

Gore F, Schwartz EC, Salzman CD. 2015b. Manipulating neural activity in physiologically classified neurons: triumphs and challenges. Philos Trans R Soc Lond B Biol Sci 370: 20140216.

Greba Q, Kokkinidis L. 2000. Peripheral and intraamygdalar administration of the dopamine D1 receptor antagonist SCH 23390 blocks fear-potentiated startle but not shock reactivity or the shock sensitization of acoustic startle. Behav Neurosci 114: 262-272.

Guzowski JF, Miyashita T, Chawla MK, Sanderson J, Maes LI, Houston FP, Lipa P, McNaughton BL, Worley PF, Barnes CA. 2006. Recent behavioral history modifies coupling between cell activity and Arc gene transcription in hippocampal CA1 neurons. Proc Natl Acad Sci 103: 1077-1082.

Hangya B, Ranade SP, Lorenc M, Kepecs A. 2015. Central cholinergic neurons are rapidly recruited by reinforcement feedback. Cell 162: $1155-1168$.

Harmer CJ, Phillips GD. 1999. Enhanced dopamine efflux in the amygdala by a predictive, but not a non-predictive, stimulus: facilitation by prior repeated D-amphetamine. Neuroscience 90: $119-130$.

Heisler LK, Zhou L, Bajwa P, Hsu J, Tecott LH. 2007. Serotonin 5-HT2C receptors regulate anxiety-like behavior. Genes Brain Behav 6: 491-496.

Hnasko TS, Edwards RH. 2012. Neurotransmitter corelease: mechanism and physiological role. Annu Rev Physiol 74: 225-243.

Hokfelt T, Arvidsson U, Cullheim S, Millhorn D, Nicholas AP, Pieribone V, Seroogy K, Ulfhake B. 2000. Multiple messengers in descending serotonin neurons: localization and functional implications. J Chem Neuroanat 18: 75-86.

Holmes A. 2008. Genetic variation in cortico-amygdala serotonin function and risk for stress-related disease. Neurosci Biobehav Rev 32: 1293-1314.

Hori K, Tanaka J, Nomura M. 1993. Effects of discrimination learning on the rat amygdala dopamine release: a microdialysis study. Brain Res 621: $296-300$

Hurd YL, McGregor A, Ponten M. 1997. In vivo amygdala dopamine levels modulate cocaine self-administration behaviour in the rat: D1 dopamine receptor involvement. Eur J Neurosci 9: 2541-2548.

Iidaka T, Ozaki N, Matsumoto A, Nogawa J, Kinoshita Y, Suzuki T, Iwata N, Yamamoto Y, Okada T, Sadato N. 2005. A variant C178T in the regulatory region of the serotonin receptor gene HTR3A modulates neural activation in the human amygdala. J Neurosci 25: 6460-6466.

Inglis FM, Moghaddam B. 1999. Dopaminergic innervation of the amygdala is highly responsive to stress. J Neurochem 72: 1088-1094.

Kawahara H, Yoshida M, Yokoo H, Nishi M, Tanaka M. 1993. Psychological stress increases serotonin release in the rat amygdala and prefrontal cortex assessed by in vivo microdialysis. Neurosci Lett 162: 81-84.

Kimura A, Stevenson PL, Carter RN, Maccoll G, French KL, Simons JP, Al-Shawi R, Kelly V, Chapman KE, Holmes MC. 2009. Overexpression of 5 -HT2C receptors in forebrain leads to elevated anxiety and hypoactivity. Eur J Neurosci 30: 299-306.

Klein RC, Yakel JL. 2006. Functional somato-dendritic $\alpha 7$-containing nicotinic acetylcholine receptors in the rat basolateral amygdala complex. J Physiol 576: 865-872.

Koyama S, Kubo C, Rhee JS, Akaike N. 1999. Presynaptic serotonergic inhibition of GABAergic synaptic transmission in mechanically dissociated rat basolateral amygdala neurons. J Physiol 518(Pt 2): 525-538.

Koyama S, Matsumoto N, Murakami N, Kubo C, Nabekura J, Akaike N. 2002. Role of presynaptic 5-HT1A and 5-HT3 receptors in modulation of synaptic GABA transmission in dissociated rat basolateral amygdala neurons. Life Sci 72: 375-387.

Kroner S, Rosenkranz JA, Grace AA, Barrionuevo G. 2005. Dopamine modulates excitability of basolateral amygdala neurons in vitro. I Neurophysiol 93: 1598-1610.

Laaris N, Le Poul E, Hamon M, Lanfumey L. 1997. Stress-induced alterations of somatodendritic 5-HT1A autoreceptor sensitivity in the rat dorsal raphe nucleus-in vitro electrophysiological evidence. Fundam Clin Pharmacol 11: 206-214.

Lalumiere RT, Nguyen LT, McGaugh JL. 2004. Post-training intrabasolateral amygdala infusions of dopamine modulate consolidation of inhibitory avoidance memory: involvement of noradrenergic and cholinergic systems. Eur J Neurosci 20: 2804-2810.

Lanfumey L, Pardon MC, Laaris N, Joubert C, Hanoun N, Hamon M, Cohen-Salmon C. 1999. 5-HT1A autoreceptor desensitization by chronic ultramild stress in mice. Neuroreport 10: 3369-3374.

Li X, Inoue T, Abekawa T, Weng S, Nakagawa S, Izumi T, Koyama T. 2006. 5-HT1A receptor agonist affects fear conditioning through stimulations of the postsynaptic 5-HT1A receptors in the hippocampus and amygdala. Eur J Pharmacol 532: 74-80.

Liu Z, Zhou J, Li Y, Hu F, Lu Y, Ma M, Feng Q, Zhang JE, Wang D, Zeng J, et al. 2014. Dorsal raphe neurons signal reward through 5-HT and glutamate. Neuron 81: 1360-1374.

Luo M, Zhou J, Liu Z. 2015. Reward processing by the dorsal raphe nucleus: 5-HT and beyond. Learn Mem 22: 452-460.

Maltais S, C té S, Drolet G, Falardeau P. 2000. Cellular colocalization of dopamine D1 mRNA and D2 receptor in rat brain using a D2 dopamine receptor specific polyclonal antibody. Prog Neuropsychopharmacol Biol Psychiatry 24: 1127-1149.

Man MS, Mikheenko Y, Braesicke K, Cockcroft G, Roberts AC. 2012. Serotonin at the level of the amygdala and orbitofrontal cortex modulates distinct aspects of positive emotion in primates. Int J Neuropsychopharmacol 15: 91-105.

Mascagni F, McDonald AJ. 2007. A novel subpopulation of 5-HT type 3A receptor subunit immunoreactive interneurons in the rat basolateral amygdala. Neuroscience 144: 1015-1024.

Matsumoto M, Hikosaka O. 2007. Lateral habenula as a source of negative reward signals in dopamine neurons. Nature 447: 1111-1115.

Matsumoto M, Hikosaka O. 2009. Two types of dopamine neuron distinctly convey positive and negative motivational signals. Nature 459: $837-841$.

McCool BA, Christian DT, Fetzer JA, Chappell AM. 2014. Lateral/ basolateral amygdala serotonin type- 2 receptors modulate operant self-administration of a sweetened ethanol solution via inhibition of principal neuron activity. Front Integr Neurosci 8: 5.

McDonald AJ, Mascagni F. 2007. Neuronal localization of 5-HT type 2A receptor immunoreactivity in the rat basolateral amygdala. Neuroscience 146: 306-320.

McDonald AJ, Mascagni F. 2010. Neuronal localization of $\mathrm{m} 1$ muscarinic receptor immunoreactivity in the rat basolateral amygdala. Brain Struct Funct 215: $37-48$

McDonald AJ, Mascagni F. 2011. Neuronal localization of M2 muscarinic receptor immunoreactivity in the rat amygdala. Neuroscience 196: 49-65.

McIntyre CK, Ragozzino ME, Gold PE. 1998. Intra-amygdala infusions of scopolamine impair performance on a conditioned place preference task but not a spatial radial maze task. Behav Brain Res 95: 219-226.

Melke J, Westberg L, Nilsson S, Landen M, Soderstrom H, Baghaei F, Rosmond R, Holm G, Bjorntorp P, Nilsson LG, et al. 2003. A polymorphism in the serotonin receptor 3A (HTR3A) gene and its association with harm avoidance in women. Arch Gen Psychiatry 60 $1017-1023$.

Miyakawa T, Yamada M, Duttaroy A, Wess J. 2001. Hyperactivity and intact hippocampus-dependent learning in mice lacking the M1 muscarinic acetylcholine receptor. J Neurosci 21: 5239-5250.

Miyazaki K, Miyazaki KW, Doya K. 2011. Activation of dorsal raphe serotonin neurons underlies waiting for delayed rewards. J Neurosci 31: $469-479$.

Miyazaki KW, Miyazaki K, Tanaka KF, Yamanaka A, Takahashi A, Tabuchi S, Doya K. 2014. Optogenetic activation of dorsal raphe serotonin neurons enhances patience for future rewards. Curr Biol 24: 2033-2040.

Montagne-Clavel J, Oliveras JL, Martin G. 1995. Single-unit recordings at dorsal raphe nucleus in the awake-anesthetized rat: spontaneous activity and responses to cutaneous innocuous and noxious stimulations. Pain 60: 303-310.

Morrison KE, Cooper MA. 2012. A role for 5-HT1A receptors in the basolateral amygdala in the development of conditioned defeat in Syrian hamsters. Pharmacol Biochem Behav 100: 592-600.

Morrison SE, Salzman CD. 2010. Re-valuing the amygdala. Curr Opin Neurobiol 20: $221-230$

Morrison SE, Saez A, Lau B, Salzman CD. 2011. Different time courses for learning-related changes in amygdala and orbitofrontal cortex. Neuron 71: $1127-1140$

Muller JF, Mascagni F, McDonald AJ. 2009. Dopaminergic innervation of pyramidal cells in the rat basolateral amygdala. Brain Struct Funct 213: $275-288$. 
Muly EC, Senyuz M, Khan ZU, Guo JD, Hazra R, Rainnie DG. 2009. Distribution of D1 and D5 dopamine receptors in the primate and rat basolateral amygdala. Brain Struct Funct 213: 375-393.

Nakamura K. 2013. The role of the dorsal raphé nucleus in reward-seeking behavior. Front Integr Neurosci 7: 60.

Nakamura K, Matsumoto M, Hikosaka O. 2008. Reward-dependent modulation of neuronal activity in the primate dorsal raphe nucleus. I Neurosci 28: 5331-5343.

Namburi P, Beyeler A, Yorozu S, Calhoon GG, Halbert SA, Wichmann R, Holden SS, Mertens KL, Anahtar M, Felix-Ortiz AC, et al. 2015. A circuit mechanism for differentiating positive and negative associations. Nature 520: 675-678.

Nassi JJ, Cepko CL, Born RT, Beier KT. 2015. Neuroanatomy goes viral! Front Neuroanat 9: 80 .

Niesler B, Flohr T, Nothen MM, Fischer C, Rietschel M, Franzek E, Albus M, Propping P, Rappold GA. 2001. Association between the 5' UTR variant C178T of the serotonin receptor gene HTR3A and bipolar affective disorder. Pharmacogenetics 11: 471-475.

Passani MB, Cangioli I, Baldi E, Bucherelli C, Mannaioni PF, Blandina P. 2001. Histamine H3 receptor-mediated impairment of contextual fear conditioning and in-vivo inhibition of cholinergic transmission in the rat basolateral amygdala. Eur J Neurosci 14: 1522-1532.

Paton JJ, Belova MA, Morrison SE, Salzman CD. 2006. The primate amygdala represents the positive and negative value of visual stimuli during learning. Nature 439: 865-870.

Peck CJ, Salzman CD. 2014a. The amygdala and basal forebrain as a pathway for motivationally guided attention. J Neurosci 34: 13757-13767.

Peck CJ, Salzman CD. 2014b. Amygdala neural activity reflects spatial attention towards stimuli promising reward or threatening punishment. Elife 3.

Peck CJ, Lau B, Salzman CD. 2013. The primate amygdala combines information about space and value. Nat Neurosci 16: 340-348.

Pickel VM, Colago EE, Mania I, Molosh AI, Rainnie DG. 2006. Dopamine D1 receptors co-distribute with N-methyl-D-aspartic acid type-1 subunits and modulate synaptically-evoked N-methyl-D-aspartic acid currents in rat basolateral amygdala. Neuroscience 142: 671-690.

Pidoplichko VI, Prager EM, Aroniadou-Anderjaska V, Braga MF. 2013. $\alpha 7$-Containing nicotinic acetylcholine receptors on interneurons of the basolateral amygdala and their role in the regulation of the network excitability. J Neurophysiol 110: 2358-2369.

Pitkanen A. 2000. Connectivity of the rat amygdaloid complex. In The amygdala: a functional analysis, 2nd ed. (ed. Aggleton JP), pp. 31-116. Oxford University Press, Oxford.

Power AE, McGaugh JL. 2002. Phthalic acid amygdalopetal lesion of the nucleus basalis magnocellularis induces reversible memory deficits in rats. Neurobiol Learn Mem 77: 372-388.

Power JM, Sah P. 2008. Competition between calcium-activated K+ channels determines cholinergic action on firing properties of basolateral amygdala projection neurons. J Neurosci 28: 3209-3220.

Power AE, McIntyre CK, Litmanovich A, McGaugh JL. 2003. Cholinergic modulation of memory in the basolateral amygdala involves activation of both $\mathrm{m} 1$ and $\mathrm{m} 2$ receptors. Behav Pharmacol 14: 207-213.

Redondo RL, Kim J, Arons AL, Ramirez S, Liu X, Tonegawa S. 2014. Bidirectional switch of the valence associated with a hippocampal contextual memory engram. Nature 513: 426-430.

Reynolds SM, Berridge KC. 2008. Emotional environments retune the valence of appetitive versus fearful functions in nucleus accumbens. Nat Neurosci 11: 423-425.

Richardson RT, DeLong MR. 1991. Electrophysiological studies of the functions of the nucleus basalis in primates. Adv Exp Med Biol 295: 233-252.

Robinson MJ, Berridge KC. 2013. Instant transformation of learned repulsion into motivational "wanting". Curr Biol 23: 282-289.

Romo R, Schultz W. 1990. Dopamine neurons of the monkey midbrain: contingencies of responses to active touch during self-initiated arm movements. J Neurophysiol 63: 592-606.

Royer S, Pare D. 2003. Conservation of total synaptic weight through balanced synaptic depression and potentiation. Nature 422: 518-522.

Rueter LE, Jacobs BL. 1996. A microdialysis examination of serotonin release in the rat forebrain induced by behavioral/environmental manipulations. Brain Res 739: 57-69.
Rygula R, Clarke HF, Cardinal RN, Cockcroft GJ, Xia J, Dalley JW, Robbins TW, Roberts AC. 2014. Role of central serotonin in anticipation of rewarding and punishing outcomes: effects of selective amygdala or orbitofrontal 5-HT depletion. Cereb Cortex 25: 3064-3076.

Schoenbaum G, Chiba AA, Gallagher M. 1999. Neural encoding in orbitofrontal cortex and basolateral amygdala during olfactory discrimination learning. J Neurosci 19: 1876-1884.

Schultz W. 2007. Behavioral dopamine signals. Trends Neurosci 30: 203-210.

Schweimer JV, Ungless MA. 2010. Phasic responses in dorsal raphe serotonin neurons to noxious stimuli. Neuroscience 171: 1209-1215.

See RE, Kruzich PJ, Grimm JW. 2001. Dopamine, but not glutamate, receptor blockade in the basolateral amygdala attenuates conditioned reward in a rat model of relapse to cocaine-seeking behavior. Psychopharmacology (Berl) 154: 301-310.

See RE, Fuchs RA, Ledford CC, McLaughlin J. 2003. Drug addiction, relapse, and the amygdala. Ann N Y Acad Sci 985: 294-307.

Shabel SJ, Janak PH. 2009. Substantial similarity in amygdala neuronal activity during conditioned appetitive and aversive emotional arousal. Proc Natl Acad Sci 106: 15031-15036.

Solomon RL, Corbit JD. 1974. An opponent-process theory of motivation. I. Temporal dynamics of affect. Psychol Rev 81: 119-145.

Stein C, Davidowa H, Albrecht D. 2000. 5-HT(1A) receptor-mediated inhibition and 5-HT(2) as well as 5-HT(3) receptor-mediated excitation in different subdivisions of the rat amygdala. Synapse 38: 328-337.

Steinbusch HW, Nieuwenhuys R, Verhofstad AA, Van der Kooy D. 1981. The nucleus raphe dorsalis of the rat and its projection upon the caudatoputamen. A combined cytoarchitectonic, immunohistochemical and retrograde transport study. J Physiol (Paris) 77: $157-174$

Stiedl O, Misane I, Spiess J, Ogren SO. 2000. Involvement of the 5-HT1A receptors in classical fear conditioning in C57BL/6J mice. J Neurosci 20: $8515-8527$.

Sugita S, Shen KZ, North RA. 1992. 5-hydroxytryptamine is a fast excitatory transmitter at 5-HT3 receptors in rat amygdala. Neuron 8: 199-203.

Tian J, Uchida N. 2015. Habenula lesions reveal that multiple mechanisms underlie dopamine prediction errors. Neuron 87: 1304-1316.

Tinsley MR, Quinn JJ, Fanselow MS. 2004. The role of muscarinic and nicotinic cholinergic neurotransmission in aversive conditioning: comparing Pavlovian fear conditioning and inhibitory avoidance. Learn Mem 11: $35-42$.

Unal CT, Pare D, Zaborszky L. 2015. Impact of basal forebrain cholinergic inputs on basolateral amygdala neurons. J Neurosci 35: 853-863.

Ungless MA, Magill PJ, Bolam JP. 2004. Uniform inhibition of dopamine neurons in the ventral tegmental area by aversive stimuli. Science 303: $2040-2042$.

Vertes RP. 1991. A PHA-L analysis of ascending projections of the dorsal raphe nucleus in the rat. J Comp Neurol 313: 643-668.

Wang SJ, Cheng LL, Gean PW. 1999. Cross-modulation of synaptic plasticity by $\beta$-adrenergic and 5-HT1A receptors in the rat basolateral amygdala. J Neurosci 19: 570-577.

Washburn MS, Moises HC. 1992. Muscarinic responses of rat basolateral amygdaloid neurons recorded in vitro. J Physiol 449: 121-154.

Womble MD, Moises HC. 1993. Muscarinic modulation of conductances underlying the afterhyperpolarization in neurons of the rat basolateral amygdala. Brain Res 621: 87-96.

Won J, Silva AJ. 2008. Molecular and cellular mechanisms of memory allocation in neuronetworks. Neurobiol Learn Mem 89: 285-292.

Yokoyama M, Suzuki E, Sato T, Maruta S, Watanabe S, Miyaoka H. 2005. Amygdalic levels of dopamine and serotonin rise upon exposure to conditioned fear stress without elevation of glutamate. Neurosci Lett 379: $37-41$.

Zhang W, Schneider DM, Belova MA, Morrison SE, Paton JJ, Salzman CD. 2013. Functional circuits and anatomical distribution of response properties in the primate amygdala. J Neurosci 33: 722-733.

Received September 14, 2015; accepted in revised form April 26, 2016. 


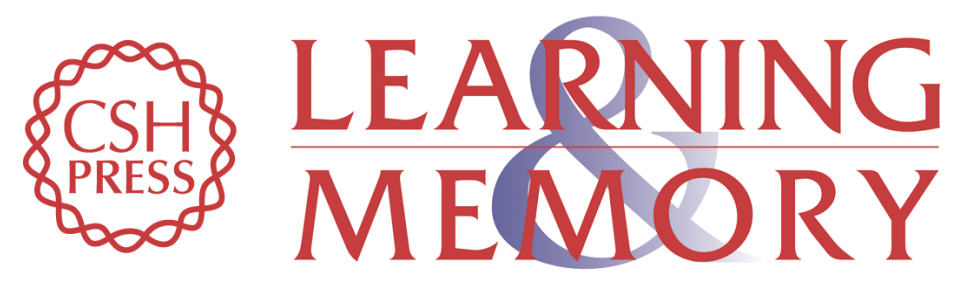

\section{Input-specific contributions to valence processing in the amygdala}

Susana S. Correia and Ki A. Goosens

Learn. Mem. 2016, 23:

Access the most recent version at doi:10.1101/Im.037887.114

References This article cites 119 articles, 22 of which can be accessed free at: http://learnmem.cshlp.org/content/23/10/534.full.html\#ref-list-1

Creative This article is distributed exclusively by Cold Spring Harbor Laboratory Press for the Commons first 12 months after the full-issue publication date (see

License http://learnmem.cshlp.org/site/misc/terms.xhtml). After 12 months, it is available under a Creative Commons License (Attribution-NonCommercial 4.0 International), as described at http://creativecommons.org/licenses/by-nc/4.0/.

Email Alerting Receive free email alerts when new articles cite this article - sign up in the box at the Service top right corner of the article or click here. 